\title{
Когнитивная педагогика
}

\section{УДК 378}

\section{Когнитивный диалог как человекообразующая стратегия образования}

\section{Cognitive dialogue as a human-forming strategy of education}

Мухаметзянова Л.Ю., ФГБНУ «Институт педагогики, психологии и соииальных проблем»,lar_ur@list.ru

Mukhametzyanova L., Institute of Pedagogy, Psychology and Social Problems, lar_ur@list.ru

\author{
DOI: 10.51379/KPJ.2021.146.3.004
}

Статья выполнена по государственному заданию № 0599-2021-0004 «Проблема современной методологии изучения формирования и развития человека в эпоху цифровизации».

Ключевые слова: сочио-когнитивный подход, принции человекосообразности, принции гармонической соразмерности, когнитивный диалог, эмоциональная идентификациия.

Keywords: social-cognitive approach, the principle of human conformity, the principle of harmonious proportionality, cognitive dialogue, emotional identification.

Аннотация. Актуальность статьи обусловлена необходимостью определения развивающих, обучающих и воспитывающих векторов когнитивного диалога, сопряженных с человеко-мерностью знания, определяющей гуманистические смысловые приоритеты Человека современного противоречивого мира. Цель статьи ввести понятие «когнитивный диалог» в проблемное поле когнитивной педагогики как человекообразующей стратегии педагогического взаимодействия, детерминирующего концептуально-иенностные образования гармоничного развития личности. Определень этапь развития диалогического самопознания в проиессе когнитивного диалога в единстве логических и эмоционально-образньх координат на материале художественных произведений. Результатом исследования явилась разработка принципов когнитивного диалога: принщипа человекосообразности, обеспечивающего развитие гуманистической рефлексии взаимодействия в рамках интеллигентного сообщества субъектов образовательного процесса; принципа гармонической соразмерности, определяющего кониептуальное гуманистическое осознание симметричного согласования личностных и сочиильных смыслов когнитивного развития человека и результативных правил их реализации в образовательной практике. Статья предназначена для педагогов, психологов, преподавателей вузов, исследователей в области современной педагогики.

Abstract. The relevance of the article is due to the need to determine the teaching, educating and developing vectors of cognitive dialogue, coupled with the human dimension of scientific knowledge, which determines the humanistic semantic priorities of the Man in the modern contradictory world. The purpose of the article is to introduce the concept of "cognitive dialogue" into the problem field of cognitive pedagogy as a human-forming strategy of pedagogical interaction, which determines the conceptual-value formations of the harmonious development of the individual. The stages of development of dialogical self-knowledge in the process of cognitive dialogue in the unity of logical and emotional-figurative coordinates on the material of works of art are determined. The result of the study was the development of effective principles of cognitive dialogue: human conformity, which ensures the development of humanistic reflection of interaction within the framework of the intelligent community of subjects of the educational process, harmonious proportionality, which determines the conceptual humanistic awareness of the symmetrical coordination of personal and social meanings of human cognitive development and the rules for their implementation in educational practice. The article is intended for teachers, psychologists, university-teachers, researchers in the field of modern pedagogy.

Введение. Актуальность исследования обусловлена тем, что особое место в развитии новых ценностей и культурных поведенческих практик человека в эпоху цифровизации занимают ценностно-смысловые приоритеты образовательной системы, которые определяют, что обучающийся является не только носителем профессиональных знаний, умений и навыков, но и человеком, имеющим особые человеческие качества и свойства, которые позволяют ему вступать в социокультурное взаимодействие.

Выдающийся немецкий педагог-гуманист середины XIX в. Фридрих Адольф Вильгельм Дистервег определяет цель образования 
следующим образом: «В каждом индивидууме, в каждой нации должен быть воспитан образ мыслей, именуемый гуманностью: это стремление к благородным общечеловеческим целям» [6, с.136]. В.С. Соловьев подчеркивает: «Под мудростью разумеется не только полнота знаний, но и нравственное совершенствование, внутренняя цельность духа» [14, с.54].

Причина многих проблем современного мира заключатся в неспособности к пониманию, уважению, принятию Другого, к абсолютизации собственной позиции как единственно верной. Поэтому одна из значимых задач современного образования - развитие диалогического мышления обучающегося. Раскрывая полифоничность произведений Ф.M. Достоевского, М.М. Бахтин писал: «Мысль человека не систематична, а диалогична. То есть она требует ответа, возражений, требует согласия и несогласия. Только в атмосфере этой свободной борьбы человеческая мысль может развиваться» [3, с.7]. Развитие диалогического мышления субъктов образования - это, прежде всего, развитие способности видеть разные точки зрения, обогащаясь и развиваясь от общения с Другим, участвовать в коллективной учебной мыследеятельности, открывая для себя различные, в том числе и противоречащие друг другу, стороны действительности.

$\begin{array}{ccc}\text { В эпоху } & \text { цифровизации } & \text { необходимы } \\ \text { принципиально } & \text { новая } & \text { организация }\end{array}$
педагогического процесса и создание условий развития личностных когнитивных механизмов, обеспечивающих формирование универсальных качеств обучающихся (self - skills), совокупность которых обусловит решение профессиональных задач. Б. Паскаль, подчеркивая значимость соразмерных когнитивных механизмов в развитии человекообразного диалогического мышления личности, говорил: «Только мысль делает человека великим ...не в пространстве могу я найти свое могущество, А в порядке своего мышления. ...В пространстве Вселенная охватывает и проглатывает меня, как маленькую точку, в мышлении я охватываю ее» [12, с.101].

Личность овладевает смыслами в реальностях предметного мира, культуры и речи посредством социального взаимодействия, определяющего исходный контекст обучения в образовательной организации высшего образования как детерминацию ценностных и смысловых преобразований в процессе формирования человекообразующих качеств и профессиональных характеристик субъектов образования. Принципиально важными становятся изучение и развитие человека в многообразии его ценностно-смыслового взаимодействия с быстро трансформирующейся «цифровой» действительностью.

Именно «человекообразующий» тип образования является глобальным инновационным резервом в развитии гуманистической рефлексии взаимодействия в рамках интеллигентного сообщества субъектов образовательного процесса. Статус интеллигентности, присущий российскому менталитету как складу ума, образу мировосприятия, позабытый, но необходимый современному Человеку. Дмитрий Сергеевич Лихачев, обладающий этим почетным статусом, писал: «Интеллигент - это человек, обладающий умственной порядочностью. Основной принцип интеллигентности - интеллектуальная свобода, свобода как нравственная категория. Не свободен интеллигентный человек только от своей совести и от своей мысли. Совесть не только ангелхранитель человеческой чести, это рулевой его свободы, она заботится о том, чтобы свобода не превращалась в произвол, но указывала человеку его настоящую дорогу» [9, с.4].

Станислав Ежи Лец, польский поэт, философ, писатель-сатирик XX века писал: «Диалог полуинтеллигентов равняется монологу четвертьинтеллигента» $[8$, с.75].

Интеллигентное сообщество субъектов образовательного процесса обеспечивает когнитивный диалог как продуктивный тип добровольных равноправных межсубъектных отношений, при котором взаимодействующие партнёры выявляют новую информацию в процессе общения и константно изменяются, при этом сохранив свою суверенность и индивидуальность.

Методология исследования. Продуктивному внедрению когнитивного диалога в образовательный процесс способствуют социокогнитивный подход и принципы человекосообразности и гармонической соразмерности.

Сущностными установками социокогнитивного подхода выступают: нацеленность на овладение человеком культуросообразными, природосообразными и профессиональными смыслами в рамках высшего образования, преобразование их в собственные концепты на основе личной способности человека к переработке новой информации и генерации знаний и развитие личностной концептосферы. Эффективное развитие данной способности человека обусловливают его когнитивные особенности - механизмы познания, определяющие усвоение им научных знаний в 
культурно-ценностном диалоге времён, концептуальных точек зрения, определяющих образ личностно-профессиональной картины мира.

Принцип

человекосообразности обусловливает ориентацию на человека (его возможности, способности, потребности и жизненную миссию) при проектировании и реализации высшего образования [7]. Принцип гармонической соразмерности определяет гуманистическую матрицу развития гармоничной личности в интеграционной целостности когнитивной устойчивости, активности, ясности, «симметрии»; соразмерности ценностносмысловых установок личности социокультурным ценностям.

Результаты исследования. Особое значение в ракурсе рассмотрения диалога как типа равноправных отношений субъектов образования, способствующих сохранению их суверенности и индивидуальности, и монолога как неотъемлемой разумной грани человеческой жизни «думать значит, прежде всего, говорить с самим собой» имеет когнитивный диалог педагога и обучающихся.

М.М. Бахтин писал, что «истина не рождается в голове отдельного человека, она рождается между людьми, совместно ищущими, в процессе их диалогического общения» [2, с.16]. Когнитивный диалог предполагает выявление отношения обучающегося к знанию, способствует проявлению личностной позиции, создает атмосферу взаимопонимания в образовательной среде, доверия, откровенности, обеспечивает форму созидания себя как познающего человека на основе взаимосвязи познавательных, ценностно-смысловых и концептных аспектов самосознания. Диалог слагается из высказываний разных лиц и осуществляется цепью лаконичных смысловых высказываний, именуемых репликами. Сократ говорил: «Если хочешь со мной беседовать, применяй краткословие» [13]. Способность вести диалог - это особая сфера речевой культуры, где от личности «требуются» чуткость к собеседнику, гибкость мысли, соответствие между умением говорить (откликаясь на ситуацию момента) и умением вслушиваться в слова рядом находящегося человека.

Когнитивный диалог - это принципиально иное явление, чем просто диалог, в основе которого лежат развернутые, пространные высказывания, знаменующие внешнюю активность субъектов образования. В основе такого диалога лежат обращенные монологи, которые воздействуют на адресата, но не требуют речевого отклика.

В основе когнитивного диалога в образовательном процессе лежит условие развития уединенных монологов личности. Уединенные монологи - неотъемлемая грань человеческой жизни. По словам В. Айрапетяна, «думать - значит, прежде всего, говорить с самим собой» [1, с.89]. Эти монологи органически связаны с тем, что Ю.М. Лотман называл «автокоммуникацией», в основе которой лежит ситуация «Я-Я», а не «Я-ОН». «Европейская культура, - утверждал ученый, - сознательно и целеустремленно ориентируется на систему «ЯОН», но есть культуры, ориентированные преимущественно на автокоммуникацию (страны Востока): они способны развивать большую духовную активность, однако часто оказываются менее динамичными» [10, с.89]. Любой участник диалога, используя смысловую автокоммуникацию после каждого высказывания, изменяет собственное состояние за счёт информационного прироста в процессе бесконечного смыслопорождения.

Когнитивный диалог субъектов образования осуществляется в гуманистическом контексте, включающем гуманистическое личностноценностное осознание образа самого себя и своей профессиональной жизнедеятельности с опорой на исходные социальные установки в практике высшего образования. Он определяет свободу личностного выражения, возможность искренно и открыто проявлять свои эмоциональные состояния, но при этом сохранять как собственное самоуважение и достоинство, так и уважение к другой личности.

Когнитивный диалог способствует формированию ассертивности как личностного качества субъектов образовательного процесса, интегрирующего человекосообразность и гармоническую соразмерность. «Ассертивность это способность человека уверенно и с достоинством отстаивать свои права, не попирая при этом прав других. Ассертивным называется прямое, открытое поведение, не имеющее целью причинить вред другим людям» $[16$, с.40]. В условиях когнитивного диалога ассертивность выступает интегративным звеном человекообразующего компонента личности и показателем соразмерности ценностной матрицы обучающих и обучаемых с культурными установками социума. Именно когнитивный диалог является условием формирования их «культуры достоинства, а не потребления» (А.Г. Асмолов). 
Обязательное условие когнитивного диалога - вопросно-ответное построение взаимодействия. Но вопросы и ответы могут иметь различную цель и направленность. В процессе диалога как простого обмена информацией программируется однозначный ответ, который почти не изменяет ни спрашивающего, ни отвечающего.

М. Бахтин и М.С. Каган [2;11] считают определяющим признаком когнитивного (смыслового) диалога равноправное взаимодействие партнёров, в процессе которого происходит их взаимное изменение и рождение нового общего смысла. Участники равноправного диалога после высказывания меняют собственное состояние.

В современных условиях быстро происходящих изменений особенно важным является умение быстро реагировать на изменения, приспосабливаться к новым условиям. He менее актуальными считаются интеллектуальные навыки, умение правильно понимать людей и их поступки, оценивать ситуацию, в которую попадает человек, установление и укрепление отношений с другими людьми. Процессы познания, включающие воображение, восприятие, память, мышление в когнитивном диалоге, основаны, прежде всего, на создании эмочуионального образа, который становится специфическим инструментом познания как внешнего, так и внутреннего мира личности. В сложную эпоху цифровизации для субъектов образовательного процесса наиболее эффективным способом создания картины мира является осуществление взаимодействия традиционных моделей эмоционально-образного восприятия с новыми возможностями, связанными с современными средствами получения информации. Эмоциональная обусловленность когнитивного диалога определяет необходимость определения инструментария, обеспечивающего ценностное осознание и смысловую регуляцию на основе интеграции когниций и эмоций субъектов образования [20;22]. В качестве такого инструментария выступает эмоциональный интеллект как связующее звено развития гуманистических смыслов, ценностного осознания, понимания и регуляции когниций и эмоций субъектов образования, влияющий на успешность их когнитивного диалога. Эмоциональный интеллект - целостное динамичное образование, интегрирующее когнитивный и эмоционально-образный компоненты познания; обеспечивающее оптимистичное ценностное осознание, понимание и смысловую регуляцию собственных эмоций и эмоций окружающих и влияющее на успешность когнитивного развития личности [19;21;23].

Осуществление саморазвития, самопознания в процессе когнитивного диалога связано с непрерывным творческим поиском новых решений, открывающих простор фантазии, воображению и дающих возможность создавать индивидуальный продукт, не бояться смелых, неожиданных поворотов в решении профессиональных задач [4;18]. Поэтому необходимо привлечение такого творческого двигателя, который способствовал бы развитию диалогического самопознания в условиях когнитивного диалога педагога и обучающихся. В качестве данного двигателя выступает искусство, обеспечивающее эмоционально-образную составляющую когнитивного диалога. Интегративная сущность эмоциональнообразного развития отражена в высказывании Д. Дидро: «Творческое воображение! Без этого качества нельзя быть ни поэтом, ни философом, ни умным человеком, ни мыслящим существом, ни просто человеком» [5, с.34]. Можно определить следующие этапы развития диалогического самопознания в процессе когнитивного диалога в единстве логических и эмоционально-ценностных координат на материале художественных произведений.

Необходимое условие первого этапа идентификация, признание «чужого» в себе «своим», а также возможность увидеть «свое» в «чужом». Потребность личностной идентификации особенно остро возникает в кризисные периоды. В психологии эти кризисы связывают с возрастными периодами или с социальными катаклизмами. Ценностнопознавательные механизмы личностного восприятия обусловлены этими двумя особенностями: субъективно-возрастными и объективно-социальными. Опору для ответов на возникшие вопросы обучающиеся ищут в «зеркалах» чужих оценок, эталонов. Поэтому личности автора и героев художественного произведения могут стать этим зеркалом. О.Уайльд определял, что «искусство - зеркало, отражающее того, кто в него смотрится» [15, с.9]. Оставив настоящему зеркалу его прямую функцию фиксировать наш внешний вид, искусство как зеркало несравненно большей оптической силы, которая дает возможность личности увидеть и понять в себе свою суть, смотрясь в героев художественного произведения как в свое отражение. При этом отличительным знамением этого процесса является то, что он призван привести в состояние смысловой гармонии духовный мир личности. 
На первом этапе важно признание позиций, точек зрения эталонов героев как своих. Проблема внутреннего спора как самопознания стала одной из основных в творчестве философа и литературоведа М. Бахтина, прежде всего в его работе «Проблемы творчества Достоевского». Бахтин показывает, что ситуация «неузнания узнания» себя - это ситуация перевода диалога «внешнего» с другим, а диалог «внутренний», диалог с самим собой. Настасья Филипповна «узнает» себя в Рогожине и в Мышкине, Иван Карамазов - в Алеше и Смердякове, Раскольников - в Соне и Свидригайлове. Но «узнать себя» в другом означает одновременное признание собственной противоречивости, порой взаимоисключающих друг друга миров [3].

Признание этих миров в качестве «своих» одновременно должно означать подведение их под какой-то общий признак. Поэтому следующий этап развития диалогического самопознания - от простого узнавания в другом к признанию общей основы диалога, несмотря на внешние различия; это период деперсонификации участников спора. На этом этапе можно говорить об общении одной личности с другой, а не представителей различных возрастов и социальных групп.

Существует и другая форма общего, которая только и может служить подлинной основой внутреннего диалога. Это конкретно-общее, предполагающее не наличие общих признаков, а наличие общего закона, связывающего различных индивидов в рамках социального целого, выявление единства личностей, а не единообразия.

Личность, осознающая себя носителем конкретно-всеобщего, не относится к себе как к чему-то законченному, «ставшему». Она сама творит свой мир, самого себя. «Быть современником - творить свое время, а не опережать его. Да, отражать его, но не как зеркало, а как щит», - писала М. Цветаева [17, c.27].

Высший этап характеризуется такой формой диалога, в которой связь спорящих сторон строится по типу конкретно-всеобщего диалога, который может стать не просто «осознанием» себя, но формой созидания себя. На этом этапе диалогической модели познавательные, ценностные и проектировочные аспекты самосознания совпадают. Диалог становится способом бытия личности.

Творческая переработка, переосмысление огромного количества информации, получаемой современными студентами, осуществляется посредством включения их в реальный процесс практической деятельности, благодаря которому и происходит когнитивный диалог. Не менее значимым является и роль педагога вуза в организации когнитивного диалога. Умение педагога преподносить информацию с новой, неординарной точки зрения, умение направить внимание обучающихся в проблемное поле неисчерпаемого познания мира дает основание для креативного диалога, который слагается из высказываний разных лиц и осуществляется цепью лаконичных высказываний. Способность вести диалог - это особая сфера речевой культуры, где от личности педагога «требуются» чуткость к собеседнику, гибкость мысли, соответствие между умением говорить (откликаясь на ситуацию момента) и умением вслушиваться в слова рядом находящегося обучающегося.

В процессе когнитивного диалога существенно меняется позиция педагога: роль преподавателя высшей школы постепенно трансформируется в роль консультанта, сталкера, в буквальном смысле этого слова. Акценты смещаются на саморегуляцию, самоуправление. Когнитивный диалог обеспечивает не просто «осознание» себя, но форму созидания себя как познающего человека на основе взаимосвязи познавательных, ценностно-смысловых и концептных аспектов самосознания. Такой диалог становится способом бытия личности, поэтому педагог - обладатель когнитивного инструментария - это педагог, способный к плодотворному познавательному поиску, быстрому принятию оригинальных решений в нестандартных ситуациях, испытывающий эмоциональный комфорт от успешности применения своих знаний и от возможности генерировать новое знание, пользуясь освоенными способами и приемами оперирования внутренними личностными ресурсами. Это педагог, обеспечивающий формирование когнитивно-мыслительных и гуманистически ориентированных поведенческих стратегий обучающихся, составляющих основу личности Человека знания - думающего человека, обладающего человекосообразностью («умственная порядочность») и гармонической соразмерностью («интеллектуальная свобода как нравственная категория»).

Заключение. Философская концепция диалога актуализирует проблему когнитивного диалога как человекообразующей стратегии образования, утверждая диалогическую природу жизни личности: «Жить - значит участвовать в диалоге: вопрошать, внимать, ответствовать, соглашаться, участвовать всею жизнью: глазами, губами, 
руками, душой, духом, всем телом, поступками» [2, с.318].

В статье определяется, что диалог является не только местом встречи идей или мнений, но и герменевтическим процессом постепенного обнаружения смысла, углубления понимания его содержания, установлением человекообразующей связи между Человеком и Человеком. В связи с этим актуализирована цель исследования - ввести понятие «когнитивный диалог» в проблемное поле когнитивной педагогики как человекообразующей стратегии развития интеллигентного педагогического сообщества субъектов образования, детерминирующего концептуально-ценностные координаты их гармоничного развития.

Данная цель позволила выявить методологические установки: социо-когнитивный подход и принципы человекосообразности и гармонической соразмерности, способствующие продуктивному внедрению когнитивного диалога в образовательный процесс.

Выработаны правила реализации принципов. Правила выступают в роли дополнительных рекомендаций к конкретному принципу.

Принции человекосообразности предполагает выполнение следующих правил:

- выявление в содержании образования проблем развития духовной сущности человека;

- учет культурно-гуманистического потенциала образовательной среды, влияющего на культурно-смысловые координаты личности обучающегося;

- определение особенностей самобытного мира обучающегося с учетом его эмоциональночувственной сферы, познавательных способностей, личностных интересов;

- человечность отношений в рамках интеллигентного сообщества субъектов образовательного процесса.

Приничип гармонической соразмерности предполагает выполнение следующих правил:
- выявление в содержании образования проблем формирования планетарного сознания и элементов общечеловеческой культуры;

- гармония социумности (внешнего плана когнитивного развития) и самости (внутреннего плана когнитивного развития) в качестве двух взимосогласованных и взаимосвязанных полюсов направленности личности на себя и на социум как двух векторов гуманистического самосозидания;

- согласованность двух ключевых проявлений гармонии-состояний частей и их компенсаторностью с целью выявления симметричного согласования личностных и социальных смыслов когнитивного развития человека;

- соотнесенность идеи рационально устроенного мира со способностью ее эмоционального переживания, отображающей суть соразмерного соотношения чувств и разума человека.

Определено, что в качестве творческого двигателя, способствующего развитию диалогического самопознания, выступает искусство, раскрывающее эмоциональнообразную составляющую когнитивного диалога и устанавливающее смысловую гармонию духовного мира человека. Выявлено, что в условиях когнитивного диалога меняется позиция педагога, которая трансформируется в роль консультанта, сталкера, обладающего когнитивным инструментарием, обеспечивающим формирование когнитивномыслительных и гуманистически ориентированных поведенческих стратегий обучающихся.

Поиск эффективных технологий установления когнитивного диалога субъектов образовательного процесса может явиться перспективным направлением дальнейших исследований.
1. Айрапетян Вардан. Герменевтические подступы к русскому слову / Вардан Айрапетян. - М.: Лабиринт, 1992. - 305 с.

2. Бахтин М.М. Эстетика словесного творчества / М.М. Бахтин. - М.: Искусство, 1986. - 444 с.

3. Бахтин М.M. Проблемы поэтики Достоевского: собр. соч.: в 7 т. / М.М. Бахтин. - М.: Русские словари: Языки славянской культуры, (2002). T.6. - C. 7-300, 466-505.

4. Белова С. Профессионализм учителя способность к нескончаемому диалогу / С. Белова // Народное образование. - 2001. - № 7. - С. 103-110.

\section{Лumepamypa:}

5. Дидро Дени. Племянник Рамо / Дени Дидро. М., ЭКСМО, 2006. - 592 с.

6. Дистервег А. Избранные педагогические сочинения / А. Дистерверг. - М.: Учпедгиз, 1956. - С. 136-203.

7. Когнитивная педагогика: учебнометодическое пособие / P.X. Гильмеева, А.P. Камалеева, А.С. Кац, Е.Ю. Левина, В.Ш. Масленникова, Л.Ю. Мухаметзянова, Т.М. Трегубова, Л.А. Шибанкова; под научной редакцией Е.Ю. Левиной. - Казань: Институт педагогики, психологии и социальных проблем, 2020. - 228 с. 
8. Лец Станислав Ежи. Непричёсанные мысли. Москва, «Искусство», 2007. - 384 с.

9. Лихачев Д.С. О русской интеллигенции. Письмо в редакцию / Д.С. Лихачев // Новый мир. 1993. - № 2. - С. 3-9.

10. Лотман Ю.М. Семиосфера / Ю.М. Лотман. С.-Петербург: «Искусство-СПБ», 2000. - 704 с. - С. 89.

11. Каган М.С. Философия культуры / М.С. Каган. - М.: Юрайт, 2019. - 353 с.

12. Паскаль Б. Мысли / Б. Паскаль. - М.: «REFLbook», 1994. - $528 \mathrm{c}$.

13. Платон. Диалоги / Платон. - М.: Риполклассик, 2017. - 576 с. - С. 81.

14. Соловьев В.С. Духовные основы жизни / В.С. Соловьев. - М.: Директ-Медиа, 2015. - 197 с.

15. Уайльд О. Портрет Дориана Грея. Личность / О. Уайльд. - М.: АСТ, 2017. - 320 с.

16. Шейнов В.П. Ассертивность и психологическое здоровье / В.П. Шейнов // Материалы научной конференции «Ананьевские чтения - 2013». СПб., 2013. - С. 371-373.

17. Цветаева М.И. Поэт и время / М.И. Цветаева. М.: Фолио, 2012. - 256 c.
18. Ячин C.E. Диалог как коммуникативный режим / С.Е. Ячин, М.Ю. Орлова // Человек. - 2001. - № 5. - C. 142-148.

19. Bechara A., Tranel D., Damasio A.R. The Handbook of Emotional Intelligence / A. Bechara, D. Tranel, A.R. Damasio // Poor judgment in spite of high intellect: Neurological evidence for emotional intelligence. Jossey-Bass, San Francisco. - 2000. - P. 192-214.

20. Davis M. Empathy: a social psychological approach / M. Davis. - Boulder: Westview Press, 1996. $44 \mathrm{p}$.

21. Feshbach N.D. Parental empathy and child adjustment/maladjustment / N.D. Feshbach, J. Strayer (Eds.) // Empathy and its development. - New York: Cambridge University Press, 1987. - P. 271-29.

22. Hargreaves A. The emotional practice of teaching / A. Hargreaves // Teaching and Teacher Education. - 14(8). - P. 835-854.

23. Salovey P. and Grewal D. The Science of Emotional Intelligence // Current Directions in Psychological Science. -Vol. 14. - № 6. - 2005. - P. 281285.

\section{References:}

1. Hayrapetyan Vardan. Hermeneutical approaches to the Russian word / Vardan Hayrapetyan. - M.: Labyrinth, 1992. - 305 p.

2. Bakhtin M.M. Aesthetics of verbal creativity / M.M. Bakhtin. - M.: Art, 1986. - 444 p.

3. Bakhtin M.M. Problems of Dostoevsky's poetics: collection of works.: in 7 volumes / M.M. Bakhtin. - M.: Russian dictionaries: Languages of Slavic culture, (2002). - T.6. - S. 7-300, 466-505.

4. Belova S. Professionalism of a teacher - the ability to endless dialogue / S. Belova // Public education. - 2001. - № 7. - S. 103-110.

5. Diderot Denis. Nephew of Rameau / Denis Diderot. - M., EKSMO, 2006. - 592 p.

6. Disterweg A. Selected pedagogical works / A. Disterweg. M.: Uchpedgiz, 1956. - S. 136-203.

7. Cognitive pedagogy: manual / R.Kh. Gilmeeva, A.R. Kamaleeva, A.S. Katz, E.Yu. Levin, V.Sh. Maslennikova, L.Yu. Mukhametzyanova, T.M. Tregubova, L.A. Shibankova; under the scientific editorship of E.Yu. Levina. - Kazan: Institute of Pedagogy, Psychology and Social Problems, 2020. - 228 p.

8. Lec Stanislav Jerzy. "Uncombed" thoughts. - Moscow, "Art", 2007. - 384 p.

9. Likhachev D.S. About the Russian intelligence. Letter to the Editor / D.S. Likhachev // New World. - 1993. - № 2. - S. 3-9.

10. Lotman Yu.M. Semiosphere / Yu.M. Lotman. - St. Petersburg: "Art-SPB", 2000. - 704 p. - S. 89.

11. Kagan M.S. Philosophy of culture / M.S. Kagan. - M.: Yurayt, 2019. - $353 \mathrm{p}$.

12. Pascal B. Thoughts / B. Pascal. - M.: "REFL-book", 1994. $-528 \mathrm{p}$.
13. Plato. Dialogues / Plato. - M.: Ripol-classic, 2017. - 576 p. - S. 81.

14. Soloviev V.S. Spiritual foundations of life / V.S. Soloviev. - M.: Direct-Media, 2015. - 197 p.

15. Wilde O. Portrait of Dorian Gray. Personality / O. Wilde. - M.: AST, 2017. - 320 p.

16. Sheinov V.P. Assertiveness and psychological health / V.P. Sheinov // Materials of the scientific conference "Ananiev Readings - 2013". - SPb., 2013. - P. 371-373.

17. Tsvetaeva M.I. Poet and Time / M.I. Tsvetaeva. - M.: Folio, 2012. - $256 \mathrm{p}$

18. Yachin S.E. Dialogue as a communicative mode / S.E. Yachin, M.Yu. Orlova // Man. - 2001. - № 5. - S. 142-148.

19. Bechara A., Tranel D., Damasio A.R. The Handbook of Emotional Intelligence / A. Bechara, D. Tranel, A.R. Damasio // Poor judgment in spite of high intellect: Neurological evidence for emotional intelligence. - Jossey-Bass, San Francisco. - 2000. - P. 192-214.

20. Davis M. Empathy: a social psychological approach / M. Davis. - Boulder: Westview Press, 1996. - 44 p.

21. Feshbach N.D. Parental empathy and child adjustment / maladjustment / N.D. Feshbach, J. Strayer (Eds.) // Empathy and its development. - New York: Cambridge University Press, 1987. P. 271-29.

22. Hargreaves A. The emotional practice of teaching / A. Hargreaves // Teaching and Teacher Education. - 14 (8). - P. 835854.

23. Salovey P. and Grewal D. The Science of Emotional Intelligence // Current Directions in Psychological Science. -Vol. 14. - № 6. - 2005. - P. 281-285.

13.00.01 - Общая педагогика, история педагогики и образования

\section{Сведения об авторе:}

Мухаметзянова Лариса Юрьевна (г. Казань, Россия), кандидат педагогических наук, доцент, старший научный сотрудник ФГБНУ «Институт педагогики, психологии и социальных проблем», еmail: lar_ur@list.ru 